\title{
Anti-Cyclic Citrullinated Peptide Antibody-Positive Meningoencephalitis in the Preclinical Period of Rheumatoid Arthritis
}

\author{
Tomoya Shibahara, b Tomonaga Matsushita ${ }^{a}$ Ryu Matsuo ${ }^{\text {b, c }}$ \\ Yoshihisa Fukushima ${ }^{a}$ Kenji Fukuda ${ }^{a}$ Hiroshi Sugimori ${ }^{d}$ \\ Masahiro Kamouchic ${ }^{c}$ Takanari Kitazono $^{\mathrm{b}}$ Tetsuro Ago ${ }^{\mathrm{b}}$ \\ ${ }^{a}$ Division of Cerebrovascular Medicine, St. Mary's Hospital, Kurume, Japan; \\ ${ }^{b}$ Department of Medicine and Clinical Science, Graduate School of Medical Sciences, \\ Kyushu University, Fukuoka, Japan; 'Department of Health Care Administration and \\ Management, Graduate School of Medical Sciences, Kyushu University, Fukuoka, Japan; \\ ${ }^{\mathrm{d}}$ Stroke Center, Saga Medical Centre Koseikan, Fukuoka, Japan
}

\section{Keywords}

Anti-cyclic citrullinated peptide antibody - Extra-articular manifestation · Rheumatoid arthritis $\cdot$ Rheumatoid meningoencephalitis

\begin{abstract}
Rheumatoid meningoencephalitis (RM) is a rare complication of rheumatoid arthritis (RA). This report describes a 63-year-old man with complaints of high-grade fever, headache, and vomiting for several days before admission. Both his serum and cerebrospinal fluid were positive for anti-cyclic citrullinated peptide (CCP) antibody and rheumatoid factor, and contrast-enhanced fluid-attenuated inversion recovery magnetic resonance imaging (MRI) showed abnormal gadolinium enhancement of the meninges and high-intensity lesions in the subarachnoid spaces. The patient was diagnosed with RM despite lack of signs suggesting RA. His symptoms drastically improved with intravenous infusion of high-dose methylprednisolone. Two months later, he developed RA. The findings in this patient suggest that
\end{abstract}




\section{Case Reports in Neurology}

Shibahara et al.: Anti-Cyclic Citrullinated Peptide Antibody-Positive Meningoencephalitis in the Preclinical Period of Rheumatoid Arthritis

RM could develop prior to the onset of RA. Anti-CCP antibody and MRI findings may be useful for the diagnosis of RM, regardless of RA history.

(C) 2016 The Author(s)

Published by S. Karger AG, Basel

\section{Introduction}

Rheumatoid meningoencephalitis (RM) is a rare extra-articular complication of rheumatoid arthritis (RA). RM usually develops in patients with a long history of RA, regardless of disease activity of systemic arthritis [1]. The diagnosis of RM is difficult because the etiology of meningitis varies and there are no definite criteria for the diagnosis of RM. Nevertheless, early diagnosis of RM is important because immunosuppressive therapies can significantly improve patient prognosis [2-4]. Magnetic resonance imaging (MRI) of the brain has been reported to be helpful for the diagnosis of RM, even during early stages [3]. Because of its high specificity, the presence of anti-cyclic citrullinated peptide (CCP) antibody is useful for the early diagnosis of RA, as well as for the prediction of future RA development in asymptomatic individuals [5]. This report describes the development of anti-CCP antibody-positive meningoencephalitis in a patient lacking a history of RA, suggesting that RM may have developed prior to the onset of RA in this patient.

\section{Case Report}

A healthy 63-year-old man was admitted to our hospital with headache, vomiting, and vertigo for several days. On admission, his body temperature was $38.5^{\circ} \mathrm{C}$, and he was slightly confused, but with normal orientation. He showed nuchal rigidity, but presented neither neurological deficits nor any signs of RA. Laboratory examinations showed a slight elevation in erythrocyte sedimentation rate $(18 \mathrm{~mm} / \mathrm{h})$ and C-reactive protein concentration $(0.4 \mathrm{mg} / \mathrm{dl})$. Examination of his cerebrospinal fluid (CSF) showed mild lymphocytic pleocytosis $\left(37\right.$ cells $\left./ \mathrm{mm}^{3}\right)$ and elevated protein concentration $(98 \mathrm{mg} / \mathrm{dl})$, but a normal glucose level. His CSF was negative for pathogens, including viruses, bacteria, mycobacteria, and fungi. Immunological tests, including antinuclear antibody, anti-neutrophil cytoplasmic antibodies against myeloperoxidase and protease 3, antibodies to double-stranded DNA, anti$\mathrm{SSa}$, and anti-SSb were all negative.

Contrast-enhanced brain MRI showed abnormal gadolinium enhancement in the bilateral frontoparietal meninges. Fluid-attenuated inversion recovery (FLAIR) images showed high-intensity lesions in the subarachnoid spaces (fig. 1a-c). Contrast CT scans of the entire body revealed no abnormal lesions. An electroencephalogram showed theta waves in the bilateral frontoparietal region without epileptic discharges.

Following a preliminary diagnosis of aseptic meningoencephalitis, he was started on empirical treatment with acyclovir $(10 \mathrm{mg} / \mathrm{kg} /$ day $)$. However, his high-grade fever persisted, and he became further disoriented and began behaving abnormally. MRI on day 8 showed that the high-intensity lesions in the bilateral frontoparietal meninges and the subarachnoid space had worsened (fig. 1d-f). The serum concentrations of both rheumatoid factor (RF) (140 IU/ml; normal $<15 \mathrm{IU} / \mathrm{ml}$ ) and anti-CCP antibody $(472 \mathrm{U} / \mathrm{ml}$; normal $<4.5 \mathrm{U} / \mathrm{ml}$ ) were significantly elevated. The CSF concentration of anti-CCP antibody was $4.4 \mathrm{U} / \mathrm{ml}$ and that of interleukin-6 (IL-6) was $482 \mathrm{pg} / \mathrm{ml}$ (normal $<12.1 \mathrm{pg} / \mathrm{ml}$ ). Although he did not fulfill the diagnostic criteria for RA at that time, he was diagnosed with RM based on the presence of anti-CCP antibody and MRI results. He was started on intravenous high-dose 
methylprednisolone treatment $(1,000 \mathrm{mg} /$ day $)$ for 3 days. By day 12 , this treatment had resulted in drastic improvements in his symptoms and reduced his high-intensity lesions on MRI. On day 13, however, he again displayed disturbed consciousness and high-grade fever, with the level of anti-CCP antibody in CSF further elevated to $26.2 \mathrm{U} / \mathrm{ml}$. He was re-treated with intravenous methylprednisolone therapy for 3 days, followed by oral administration of $50 \mathrm{mg} /$ day prednisolone, with the latter subsequently tapered. His symptoms gradually resolved along with reductions in CSF concentrations of anti-CCP antibody $(8.5 \mathrm{U} / \mathrm{ml})$ and IL-6 $(15.2 \mathrm{pg} / \mathrm{ml})$ as well as serum concentrations of $\mathrm{RF}(60 \mathrm{IU} / \mathrm{ml})$ and anti-CCP antibody (248 U/ml). MRI on day 41 showed no meningeal abnormalities in the frontoparietal lobes (fig. $1 \mathrm{~g}-\mathrm{i}$ ), and the patient was discharged on day 51.

Two months later the patient, while continuing on $30 \mathrm{mg} /$ day prednisolone, was readmitted due to metacarpophalangeal arthritis. Laboratory data demonstrated increases in white blood cell count $(13,720 / \mu \mathrm{l})$, C-reactive protein $(5.7 \mathrm{mg} / \mathrm{dl}), \mathrm{RF}(568 \mathrm{IU} / \mathrm{ml})$, as well as anti-CCP antibody in serum $(877 \mathrm{U} / \mathrm{ml})$ and CSF $(10.7 \mathrm{U} / \mathrm{ml})$. These findings met the diagnostic criteria for RA.

\section{Discussion}

This report describes a patient with aseptic meningoencephalitis developing 2 months before the onset of RA. MRI findings and the presence of anti-CCP antibody highly suggested that the meningoencephalitis was RM.

Pathophysiologically, RM is thought to be caused by microvasculitis associated with RA $[6,7]$. Microscopic examination demonstrated rheumatoid nodules, nonspecific meningeal inflammation, and vasculitis, as well as lymphocyte and plasma cell infiltration of small vessel walls. Most patients with RM have long-standing RA before the onset of RM [2-4] and show elevated RF in serum and CSF $[8,9]$. However, there are no definitive diagnostic criteria or specific diagnostic markers for RM. Although a brain biopsy is usually required to diagnose this condition, limited tissue sampling cannot always show the specific pathological features of RM, such as rheumatoid nodules. Our patient could not be diagnosed with RM on admission because he had no history of RA or articular manifestations. To our knowledge, there has been only one case report describing a patient with rheumatoid pachymeningitis preceding the onset of RA [10]. That patient was a 67-year-old man who presented with acute sensorineural hearing loss. MRI with enhancement showed diffuse thickening of the dura matter. His serum was positive for high-titer RF, but negative for anti-CCP antibody. Although that patient was treated with prednisolone and methotrexate, he manifested RA 3 months later without recovery of hearing loss. Although both this patient and ours showed elevated serum RF and abnormal MRI findings, the previous patient was negative for antiCCP antibody, whereas ours was positive.

RM may be considered in the differential diagnosis of aseptic meningitis in patients with RA and the following features: (1) high-intensity lesions are present in the subarachnoid spaces on FLAIR or diffusion-weighted images, (2) leptomeningeal abnormalities are focal, (3) the basal cisterns are usually not affected, (4) the response to corticosteroid is rapid, and (5) serum is positive for anti-CCP antibody [11]. These features may also apply to patients without a history of RA. The presence of anti-CCP antibody may be particularly important for the diagnosis of RA because of its high specificity (96\%) [12]. Anti-CCP antibody can also be useful in the diagnosis of the preclinical period of RA [5, 13]. The presence of autoantibody prior to articular manifestations of RA may indicate that immune dysregulation occurs prior 
to symptom onset [14]. The presence of anti-CCP antibody can predict the development of articular RA in patients with lung disorders, such as interstitial lung disease and certain diseases of the airways [15]. Thus, the combination of anti-CCP antibody in serum and MRI findings may be useful in diagnosing RM prior to the onset of RA.

In conclusion, the findings in this patient suggest that RM can develop in patients without a history of RA. The presence of anti-CCP antibody in serum, along with MRI, is helpful for the diagnosis of RM.

\section{Statement of Ethics}

The authors have no ethical conflicts to disclose.

\section{Disclosure Statement}

The authors state that they have no conflicts of interest.

\section{References}

1 Inan AS, Masatlioglu S, Ozyurek SC, Engin D, Erdem I: Unusual central nervous system involvement of rheumatoid arthritis: successful treatment with steroid and azathioprine. Rheumatol Int 2011;31: $1383-1385$.

2 Kato T, Hoshi K, Sekijima Y, Matsuda M, Hashimoto T, Otani M, Suzuki A, Ikeda S: Rheumatoid meningitis: an autopsy report and review of the literature. Clin Rheumatol 2003;22:475-480.

-3 Shimada K, Matsui T, Kawakami M, Hayakawa H, Futami H, Michishita K, Takaoka H, Ikenaka T, Komiya A, Nakayama H, Hagiwara F, Sugii S, Furukawa H, Ozawa Y, Tohma S: Diffuse chronic leptomeningitis with seropositive rheumatoid arthritis: report of a case successfully treated as rheumatoid leptomeningitis. Mod Rheumatol 2009;19:556-562.

4 Matsushima M, Yaguchi H, Niino M, Akimoto-Tsuji S, Yabe I, Onishi K, Sasaki H: MRI and pathological findings of rheumatoid meningitis. J Clin Neurosci 2010;17:129-132.

-5 van Venrooij WJ, Zendman AJ, Pruijn GJ: Autoantibodies to citrullinated antigens in (early) rheumatoid arthritis. Autoimmun Rev 2006;6:337-341.

6 Bathon JM, Moreland LW, DiBartolomeo AG: Inflammatory central nervous system involvement in rheumatoid arthritis. Semin Arthritis Rheum 1989;18:258-266.

7 Servioli MJ, Chugh C, Lee JM, Biller J: Rheumatoid meningitis. Front Neurol 2011;2:84.

-8 Markenson JA, McDougal JS, Tsairis P, Lockshin MD, Christian CL: Rheumatoid meningitis: a localized immune process. Ann Intern Med 1979;90:786-789.

-9 Smolen JS, Aletaha D, Grisar J, Redlich K, Steiner G, Wagner O: The need for prognosticators in rheumatoid arthritis. Biological and clinical markers: Where are we now? Arthritis Res Ther 2008;10: 208.

10 Starosta MA, Brandwein SR: Clinical manifestations and treatment of rheumatoid pachymeningitis. Neurology 2007;68:1079-1080.

11 Koide R, Isoo A, Ishii K, Uruha A, Bandoh M: Rheumatoid leptomeningitis: rare complication of rheumatoid arthritis. Clin Rheumatol 2009;28:1117-1119.

12 Whiting PF, Smidt N, Sterne JA, Harbord R, Burton A, Burke M, Beynon R, Ben-Shlomo Y, Axford J, Dieppe P: Systematic review: accuracy of anti-citrullinated peptide antibodies for diagnosing rheumatoid arthritis. Ann Intern Med 2010;152:456-464; W155-W166.

$\$ 13$ Avouac J, Gossec L, Dougados M: Diagnostic and predictive value of anti-cyclic citrullinated protein antibodies in rheumatoid arthritis: a systematic literature review. Ann Rheum Dis 2006;65:845-851.

14 Gizinski AM, Mascolo M, Loucks JL, Kervitsky A, Meehan RT, Brown KK, Holers VM, Deane KD: Rheumatoid arthritis (RA)-specific autoantibodies in patients with interstitial lung disease and absence of clinically apparent articular RA. Clin Rheumatol 2009;28:611-613. 


\section{Case Reports in Neurology}

15 Fischer A, Solomon JJ, du Bois RM, Deane KD, Olson AL, Fernandez-Perez ER, Huie TJ, Stevens AD, Gill MB, Rabinovitch AM, Lynch DA, Burns DA, Pineiro IS, Groshong SD, Duarte Achcar RD, Brown KK, Martin RJ, Swigris JJ: Lung disease with anti-CCP antibodies but not rheumatoid arthritis or connective tissue disease. Respir Med 2012;106:1040-1047.

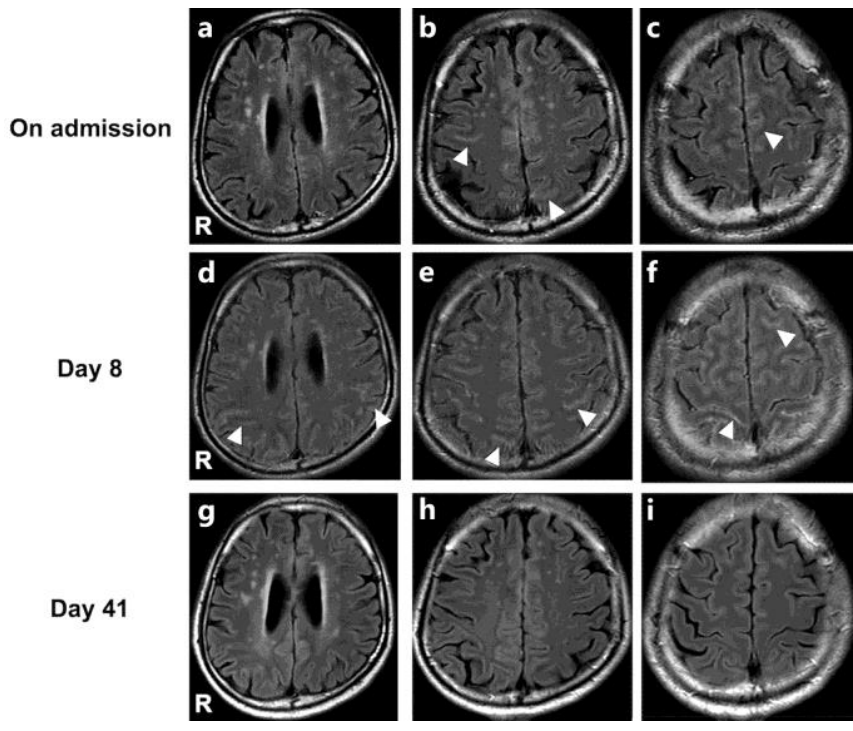

Fig. 1. Gadolinium-enhanced FLAIR images (axial, $1.5 \mathrm{~T}$; TR 8,000 ms, TE $107 \mathrm{~ms}$ ) of the patient's brain a-c FLAIR images on admission, showing abnormal gadolinium enhancement in the bilateral frontoparietal meninges with sulcal effacement and areas of hyperintensity in the underlying cortex (arrowheads). d-f FLAIR images on day 8, showing exacerbation of the hyperintense signals in the bilateral frontoparietal meninges (arrowheads). g-i FLAIR images on day 41, showing improvements in the abnormalities in the bilateral frontoparietal meninges. 